\title{
Memorabilia: aplicativo de realidade aumentada para suporte a pessoas com transtornos neurocognitivos
}

\author{
André G. de Mello Alves \\ Department of Informatics \\ PUC-Rio \\ Rio de Janeiro, Brazil \\ andre.g.melloalves@gmail.com
}

\author{
Greis Francy M. Silva-Calpa \\ Tecgraf Institute \\ PUC-Rio \\ Rio de Janeiro, Brazil \\ greis@tecgraf.puc-rio.br
}

\author{
Alberto Barbosa Raposo \\ Department of Informatics \\ PUC-Rio \\ Rio de Janeiro, Brazil \\ abraposo@tecgraf.puc-rio.br
}

\begin{abstract}
Memorabilia is an augmented reality iOS application that implements a virtual memory palace in order to help people with neurocognitive disorders to remember emotional memories and perform daily tasks. The application uses the cell phone camera to map the environment and interact with the virtual elements, and the user's personal library to personalize the experience with audiovisual reminders. The application seeks to encourage the user to explore, reason, memorize and move in an interactive and autonomous way. Tests were carried out during development. Final tests with the target audience will be carried out later.
\end{abstract}

Index Terms-Augmented Reality, Neurocognitive Disorders, Mobile Application, Memory Palace, Method of Loci

Resumo-O Memorabilia é um aplicativo iOS de realidade aumentada que implementa um palácio da memória virtual com o objetivo de auxiliar pessoas com transtornos neurocognitivos a recordarem memórias afetivas e a realizarem tarefas cotidianas. $O$ aplicativo utiliza a câmera do celular para mapear o ambiente e interagir com os elementos virtuais, e a biblioteca pessoal do usuário para personalizar a experiência com lembretes audiovisuais. $O$ aplicativo busca estimular o usuário a explorar, raciocinar, memorizar e se movimentar de forma interativa e autônoma. Foram realizados testes no decorrer do desenvolvimento. Testes finais com o público-alvo serão realizados posteriormente.

Palavras-chave-Realidade aumentada, transtornos neurocognitivos, aplicativo móvel, palácio da memória, método de loci.

\section{INTRODUÇÃO}

Transtornos Neurocognitivos (TNC) representam alteração ou déficits cognitivos nas funções cerebrais supremas [1]. Os TNC, que envolvem o anteriormente conhecido por demência (ainda pode ser aplicado aos subtipos específicos de TNC) [2], são uma das principais causas de deficiência e dependência entre pessoas mais velhas ao redor do mundo. Estes transtornos atingem aproximadamente 50 milhões de pessoas atualmente, e esse número deve crescer para 152 milhões até 2050 [3].

As pessoas com TNC podem, geralmente, esquecer como realizar tarefas cotidianas, resultando na sequência incorreta de passos ou na omissão total da tarefa [4]. Isso acontece porque elas possuem déficit nos processos cognitivos, que inclui comprometimento na percepção, memória, emoção, intenção, auto representação, racionalidade, tomada de decisão ou similares [5], o qual pode impactar negativamente, não apenas as pessoas com o diagnóstico, mas também seus cuidadores e famílias.

Tecnologias como realidade virtual (RV) e a realidade aumentada (RA) têm amadurecido rapidamente e hoje são muito comuns para fins de entretenimento, treinamento, educação e saúde, sendo aplicáveis com diversos propósitos, inclusive no suporte a pessoas com TNC.

As experiências de RV normalmente dependem de aparato robusto como capacetes, óculos, fones de ouvido, sensores e muitas vezes cabos e computadores dedicados que encarecem a experiência e dificultariam a utilização da solução pelo público-alvo. Em contrapartida, para criar uma experiência de RA, é necessário apenas uma interface entre os mundos real e virtual, sendo um dispositivo com câmera, tela e alto-falantes suficiente para oferecer uma experiência satisfatória. Apesar de uma aplicação RA também exigir alto poder computacional, a maioria dos celulares atuais têm a capacidade de desempenho necessária.

A partir desse cenário, este trabalho propõe o desenvolvimento de um aplicativo móvel de RA para o aprimoramento das habilidades cognitivas, como memória, emoção, percepção e mobilidade de pessoas com TNC. A solução proposta implementa um palácio da memória virtual com o objetivo de auxiliar pessoas com TNC a recordarem memórias afetivas e a realizarem tarefas cotidianas. As vantagens da RA sobre a RV neste cenário são observadas na facilidade de uso, no consumo de bateria, e na interação com ambientes familiares. O aplicativo foi desenvolvido para plataforma iOS, sistema operacional para celulares da Apple, fazendo-se uso de variados frameworks nativos da plataforma como ARKit, SceneKit, Photos e outras bibliotecas externas.

Os testes indicam que as pessoas com TNC, com estímulo, se interessam em aprender sobre novas tecnologias e experiências. Entretanto, é necessário prover assistência para manter o entendimento e engajamento. 


\section{BACKGROUND}

Nesta seção serão detalhados alguns conceitos aplicados na solução proposta e estudos realizados para avaliar o uso da tecnologia no suporte a pessoas com TNC.

\section{A. Método de Loci}

Entre as diferentes abordagens para facilitar a memorização, está o Método de Loci, também conhecido como palácio da memória [6]. O Método de Loci é um método mnemônico de aprimoramento de memória que combina memória espacial e um ambiente familiar para recordar informações. Ele consiste em guardar informações, desde dígitos até ideias mais complexas, em locais conhecidos para facilitar a recordação posterior. De acordo com Maguire et al. [7], isso acontece porque a memória e memória espacial ativam a mesma região do cérebro, o hipocampo. Conforme um estudo realizado por Dalgleish et al. [8] para avaliar o Método de Loci como uma ferramenta mnemônica para facilitar a lembrança de memórias autobiográficas para indivíduos com depressão, o uso dessas técnicas pode facilitar acesso a memórias pré-identificadas com uma semana de treinamento, o que pode causar impacto positivo auto reportado no humor.

\section{B. Realidade virtual e Aumentada}

De acordo com [9], para avaliar os benefícios do conceito do palácio da memória com o uso de RV, a tecnologia pode ajudar na aplicação da técnica e, consequentemente, na memorização. Os autores avaliaram com quinze pessoas, que foram orientadas a decorar itens de uma lista e de um palácio da memória. Os resultados mostram que as pessoas gostaram da experiência e ficaram surpresas com quão bem o método funcionou. Os autores destacam que os resultados indicam fortemente que a técnica de palácio da memória virtual beneficia a memória de longo prazo.

Seguindo na mesma linha, em [10] foi avaliado o impacto na imersão num ambiente em RV na aplicação do Método de Loci. Os autores aplicaram testes com dois grupos de estudantes, ao primeiro foi apresentado um palácio da memória em um computador de mesa e ao segundo foram entregues óculos de RV. Cada participante recebeu uma lista de onze palavras e deveria decorar apenas cinco. Os resultados indicaram parcialmente um desempenho levemente melhor em RV, o que os autores destacam como uma tendência de vantagem da maior imersão, e que o desenvolvimento de novas abordagens é promissor [10].

De acordo com o estudo de Wijma et al. [11] sobre uso de RV para melhorar o entendimento e empatia com pessoas com TNC por cuidadores, a tecnologia pode impactar positivamente no suporte a elas. $\mathrm{O}$ estudo consistiu em uma intervenção de RV em um formato de vídeo e curso eletrônico. Ele foi conduzido com trinta e cinco pessoas e os resultados indicam que os participantes gostaram da intervenção e a tecnologia pode auxiliar os cuidadores no cuidado e tratamento das pessoas com TNC, por meio do melhor relacionamento e interações mais positivas.
Para criar ambientes amigáveis de RA, a preocupação é ainda maior para aplicações voltadas ao público mais velho, maioria das pessoas com TNC, pois eles devem atender às seguintes condições, segundo Saracchini et al. [12]:

- O sistema deve determinar a localização do usuário em tempo real, exibindo o conteúdo automaticamente.

- O sistema deve ser viável para centros de cuidados sem depender de infraestrutura complexa ou equipamento caro.

- O usuário deve interagir com o sistema através de uma interface adaptada ao seu nível cognitivo.

- O sistema deve agir como ponte entre o dispositivo, o usuário final e sua família ou cuidadores, sem mudar a rotina do usuário ou reduzir mobilidade.

- O sistema deve produzir mudança mínima no ambiente, sem a necessidade de marcadores físicos.

\section{TRabalhos Relacionados}

Rosello et al. [13] criaram um protótipo que integra palácio da memória e realidade aumentada (RA), chamado Nevermind. Um estudo foi realizado com catorze estudantes para avaliar o desempenho do protótipo. Os participantes foram divididos em dois grupos: um utilizou o Nevermind e outro utilizou papel. Os resultados dos testes apontaram que os estudantes que utilizaram o Nevermind guardaram as informações por mais tempo que o método tradicional com papel, e que o engajamento foi muito maior. Essa aplicação e estudo são muito interessantes para este projeto, porém, essa abordagem com óculos RA não conforma com as condições necessárias já citadas para um ambiente amigável de RA.

O Ctrl Group, uma empresa que cria produtos digitais de saúde e conduz pesquisas médicas inovadoras, criou um protótipo de uma aplicação durante um período de transição entre projetos. O protótipo chamado LifeTagger [14] permite que o usuário marque em AR objetos pessoais para adicionar informações adicionais. O protótipo se aproxima do aplicativo Memorabilia, portanto é um objeto de interesse e inspiração, entretanto, é apenas um protótipo.

Existe um aplicativo para smartphones chamado $A$ Walk Through Dementia [15], criado por Alzheimer's Research UK, que permite que os usuários utilizem óculos RV para assistirem a um vídeo $360^{\circ}$ do YouTube a partir da perspectiva de uma pessoa com demência. $\mathrm{O}$ vídeo adiciona artefatos visuais como pontos escuros, latência, borrões, entre outros, assim como pensamentos em voz alta, com o objetivo de que familiares e cuidadores consigam ter uma experiência aproximada a de uma pessoa com demência para criar empatia e assim tentar melhorar a qualidade de vida delas. Esse aplicativo é muito relevante para o tema, entretanto, essa abordagem não inclui diretamente o uso por parte da pessoa com TNC, tratando-se apenas de uma campanha de conscientização sobre a doença.

A empresa Camanio Care vende produtos eletrônicos para apoio à saúde e reabilitação cognitiva, entre eles o BikeAround [16], que consiste em uma experiência VR que utiliza uma bicicleta e uma tela de projeção em formato de domo. São projetadas na tela imagens do Google Street View de lugares que a pessoa gostaria de ir ou mesmo lugares familiares 
enquanto a pessoa pedala. De acordo com um estudo feito pela própria empresa [17], o exercício físico combinado com o estímulo da memória melhora a qualidade de vida das pessoas com TNC. Trinta e sete pessoas participaram do estudo, que totalizou 147 sessões de terapia, e reportaram o benefício do engajamento dos cuidadores e familiares.

Os estudos referenciados evidenciam o potencial do uso da RA no tratamento de pessoas com TNC. Contudo, ainda não é possível encontrar uma aplicação de RA que tenha sido desenvolvida com o foco em ajudar no cotidiano das pessoas com TNC. Os poucos produtos existentes no mercado revelam as carências do mercado de tecnologia para terceira idade e com algum comprometimento cognitivo, principalmente do mercado nacional.

\section{O MEMORABILIA}

A seguir descreve-se em que consiste o aplicativo Memorabilia, os objetivos do projeto, um cenário de utilização e aspectos de implementação.

\section{A. Descrição}

O Memorabilia é um aplicativo de RA para iOS que consiste em uma biblioteca de experiências RA que podem ser criadas e customizadas pelos próprios usuários. O aplicativo utiliza a câmera e os sensores do celular para mapear o ambiente e posicionar âncoras sem necessidade de marcadores e a tela para exibir o conteúdo RA nas âncoras.

O usuário pode se movimentar no ambiente para explorar todas as âncoras e interagir com o conteúdo delas por meio de gestos na tela do seu celular. Quando uma experiência é salva, todas as âncoras e os componentes virtuais permancem atrelados às suas respectivas posições e orientações no mundo real. Para consumir uma experiência criada, basta voltar ao ambiente pois o mundo RA é automaticamente carregado na configuração original.

Este projeto buscou criar um aplicativo de celular que, visto fora do contexto, pode ser confundido com um aplicativo comercial, que não necessariamente está relacionado a pessoas idosas ou com algum tipo de TNC, porém utiliza o Método de Loci como forma de memorização e a RA como forma de entretenimento e experimentação.

Tendo em vista o desafio enfrentado diariamente pelas pessoas com TNC e os trabalhos relacionados, os seguintes objetivos foram almejados por este projeto.

1) Memória: O principal conceito explorado pelo Memorabilia é a memória, como o nome entrega. Por isso, no aplicativo, uma experiência RA também é chamada de memória, e nela é possível adicionar lembretes multimídia, mostrados na Figura 1, que podem assumir a forma de texto, foto, vídeo ou música para personalizar o ambiente real. Ao associar os diferentes tipos de memória e o Método de Loci, de acordo com os artigos citados, espera-se que o aplicativo potencialize a memorização de quaisquer informações que sejam guardadas na experiência RA.
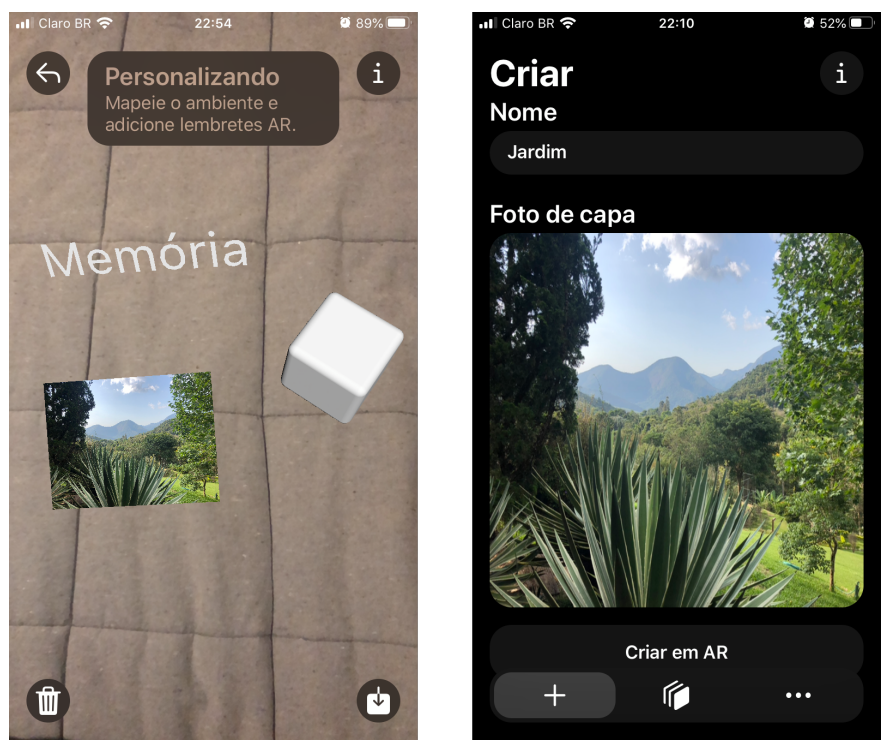

Figura 1. Exemplos de tipos de lembretes: texto, foto e música-cubo branco (esquerda) e tela de criação da memória (direita).

2) Emoção: Outro conceito muito empregado no projeto é a emoção. Para tanto, o aplicativo utiliza as bibliotecas de fotos, vídeos e músicas da pessoa com TNC salvas no próprio dispositivo. A principal consequência disso é a facilidade de personalizar as experiências com memórias vividas e despertar novas emoções ao relembrá-las durante o uso do aplicativo.

3) Percepção espacial: Uma das principais características da RA, o ambiente real é amplamente usado em conjunto com o Método de Loci para aprimorar a cognição a partir da memória espacial. Por causa deste fato, a percepção espacial também pode apresentar ganhos com o uso do aplicativo.

4) Mobilidade: Outra área complementar que é bastante beneficiada pela utilização da RA no projeto é a mobilidade. Para que todo o ambiente real/virtual seja explorado pela pessoa com TNC, é necessário que ela se movimente entre todos os lembretes posicionados nas âncoras de RA. Mesmo que o exercício não seja intenso, apenas o fato de se levantar e andar durante alguns minutos já pode ser proveitoso.

5) Interação social: Um dos objetivos do projeto e, em parte, consequência da utilização de uma tecnologia recente e desconhecida por muitas pessoas é a interação social. Além disso, muito provavelmente a pessoa com TNC precisará de ajuda para compreender todos os aspectos envolvidos na utilização do aplicativo, e por isso, precisará de assistência do cuidador ou familiar para aprender a navegar pelas funcionalidades e explorar possivelmente sua primeira experiência RA. Além disso, com interação social em mente, o aplicativo foi desenhado principalmente para que uma experiência seja criada por outra pessoa sem comprometimento cognitivo, e promover interações sociais e entre gerações.

6) Independência: Uma preocupação do Memorabilia é tentar ao máximo dar autonomia à pessoa com TNC durante o uso, por meio de uma tela de ajuda (Figura 2), com acesso disponível por qualquer parte do sistema com informações e 


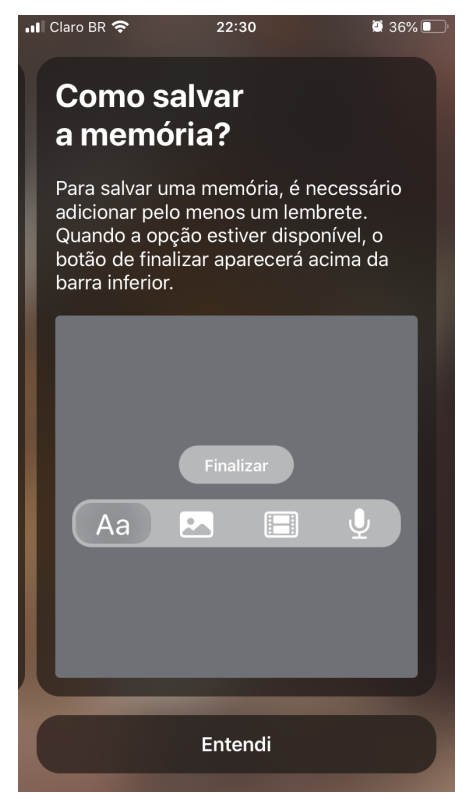

Figura 2. Tela de assistência ao usuário do Memorabilia.

dicas de uso e evitar que ela se frustre ao utilizar o aplicativo.

7) Personalização: Com o intuito de suportar a personalização da experiência, o aplicativo permite o uso de um plano de fundo para o menu principal, assim como a alteração das cores das âncoras RA. O objetivo é que isso aumente a identificação da pessoa com TNC com a tecnologia, um tema que ainda pode ser distante para muitos desses usuários, além do engajamento delas com o aplicativo.

\section{B. Cenário de utilização}

Seja o usuário um cuidador ou familiar que convive com uma pessoa com TNC, com o Memorabilia é possível criar uma experiência RA em um ambiente familiar para o paciente, como uma sala de estar. Neste caso, se o usuário quiser lembrar a pessoa com TNC como ligar a televisão, é possível ancorar um lembrete virtual de vídeo de como ligá-la no lugar da televisão no ambiente real, como mostra a Figura 3.

Caso precise lembrá-la da gaveta onde ficam os controles, pode-se criar uma âncora de texto sobre ela. Também é possível posicionar um lembrete musical em um porta-retratos para relembrá-la da música que tocava no momento em que a foto foi tirada. E se o usuário quiser adicionar alguém que faltou aparecer na foto, basta adicionar uma âncora de foto no canto do porta-retratos para a família parecer completa.

O usuário pode interagir e movimentar as âncoras por meio de gestos e utilizar a própria biblioteca do dispositivo para customizar a memória criada. Com a experiência salva no aplicativo, a pessoa com TNC consegue andar pelo ambiente real ao mesmo tempo que explora os lembretes deixados pelo usuário criador da experiência no ambiente virtual. Certamente familiares e cuidadores não são os únicos que podem criar experiências RA, inclusive as pessoas com TNC podem e devem ser encorajadas a criarem suas próprias memórias no Memorabilia.
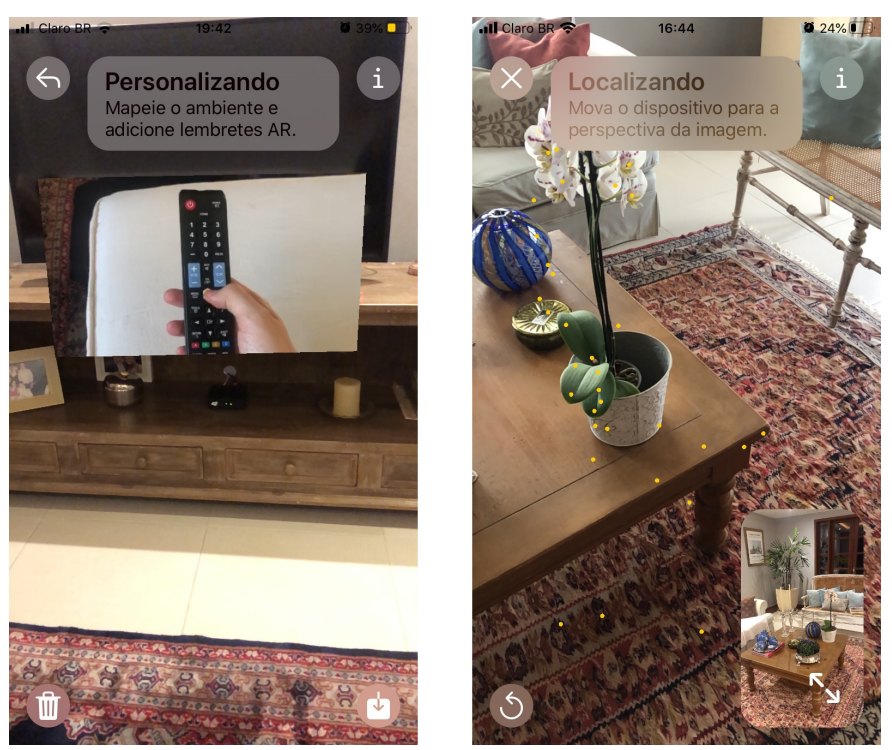

Figura 3. Exemplo de lembrete de vídeo - sobre como ligar a televisão (esquerda) e relocalização de experiência salva (direita).

\section{Desenvolvimento}

O aplicativo foi desenvolvido com as bibliotecas de RA da Apple. O ARKit é utilizado para configurar as âncoras, mapeamento de mundo e salvamento de sessão, enquanto o SceneKit é usado para renderizar os componentes virtuais como formas geométricas, fotos e vídeos. Para manipular as mídias pessoais do usuário, o Memorabilia usa o Photos e MediaPlayer. Além disso, foram necessárias várias ferramentas e tecnologias de persistência de dados, para atender às diferentes necessidades do conteúdo, armazenamento, disponibilidade e privacidade impostas pelo sistema operacional.

\section{AvaliaçÃo}

Neste estudo realizamos avaliações no decorrer do desenvolvimento, visando a criação do aplicativo com características que atendam melhor o público-alvo. Cabe notar que neste estudo não realizamos uma avaliação final do aplicativo, isto devido a dificuldades advindas da pandemia Covid-19, principalmente porque o estudo envolve usuários mais vulneráveis. A seguir detalham-se os testes realizados durante o desenvolvimento do Memorabilia.

\section{A. Protótipo de baixa fidelidade}

Criamos um protótipo para modelar a experiência do aplicativo, como seriam as interações entre o ambiente real e o virtual e quais seriam as limitações. Neste protótipo, simulamos uma experiência de RA com papéis amarelos post-it para imitar as âncoras, e espalhamos pelo ambiente para que a pessoa com TNC pudesse explorar os lembretes (Figura 4). Estes testes foram feitos com um idoso com TNC e outro sem TNC. Os testes indicaram que o engajamento não se mantém por muito tempo, por isso as interações devem ser rápidas e simples. 


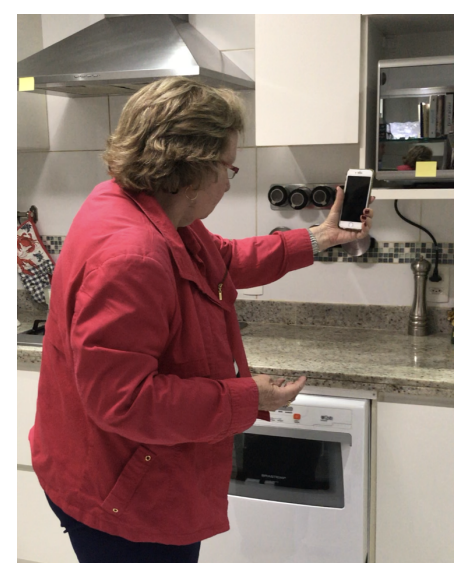

Figura 4. Teste de protótipo com post-it com público-alvo.

\section{B. Teste de interface}

Antes de iniciar a programação do aplicativo, realizamos protótipos de interface de média e alta fidelidade. A ferramenta de prototipação utilizada foi o Sketch, um software que possui bibliotecas de ícones e componentes padrões do sistema e facilitam a reprodução fiel do resultado final. Os testes foram realizados com duas pessoas que podem ter o papel de cuidador do usuário com TNC. Eles revelaram algumas dificuldades que posteriormente foram ajustadas e acrescentadas como dicas na tela de ajuda do aplicativo. Entre elas, os usuários indicaram terem tido dificuldade ao acrescentar os lembretes nas experiências de RA, por não conseguir identificar facilmente os locais que já tinham sido mapeados. Para facilitar a visualização das superfícies já mapeadas, acrescentamos pontos amarelos que indicam as possíveis posições às quais os lembretes podem ser adicionados. A tela de ajuda também sugere que todo o cômodo seja mapeado antes que o usuário comece a customizar a experiência.

\section{CONCLUSÕES}

Propomos neste estudo o Memorabilia, um aplicativo em RA que visa apoiar pessoas com TNC para recordar informações. Os testes realizados durante o desenvolvimento mostram que criar uma aplicação para pessoas com TNC pode ser desafiador porque geralmente não estão muito acostumados com tecnologia. Entretanto, ao estimular a interação, eles se mostram muito interessados e curiosos por novas experiências. Também mostram que é imprescindível o envolvimento do público-alvo desde a concepção do projeto e a adaptação do desenvolvimento de acordo com as novas evidências.

Durante o desenvolvimento do Memorabilia enfrentamos diversos desafios e identificamos alguns pontos que podem ser aperfeiçoados em trabalhos futuros. Em primeiro lugar, as interações com gestos para orientar e posicionar os lembretes no momento de criação das experiências ainda estão irregulares e pouco suaves, pode ser difícil de dominá-las. Outro item que pode ser melhorado é a tela de informações. Ao invés de exibir apenas fotos, as informações poderiam apresentar vídeos explicativos para melhorar o entendimento da interface e usabilidade do aplicativo.

Identificamos também muitas oportunidades na área de tecnologia para idosos e para pessoas com TNC. Como observado anteriormente, a quantidade de pessoas nesses grupos cresce em um ritmo muito maior que novos produtos e serviços são criados com foco neles, principalmente no Brasil, que carece de opções de aplicativos nacionais ou traduzidos. As tecnologias mais novas, como RA, representam um mercado ainda menos saturado. As diferentes aplicações possíveis para a RA ainda não foram totalmente exploradas e são temas de possíveis trabalhos futuros.

\section{REFERÊNCIAS}

[1] A. P. Association et al., Diagnostic and statistical manual of mental disorders (DSM-5®). American Psychiatric Pub, 2013.

[2] Á. C. Araújo and F. Lotufo Neto, "A nova classificação americana para os transtornos mentais: o dsm-5," Revista brasileira de terapia comportamental e cognitiva, vol. 16, no. 1, pp. 67-82, 2014.

[3] W. H. Organization et al., "Dementia fact sheet," World Health Organization: Geneva, Switzerland, 2017.

[4] J. Hayhurst, "How augmented reality and virtual reality is being used to support people living with dementia-design challenges and future directions," in Augmented reality and virtual reality. Springer, 2018, pp. 295-305

[5] A. Newen, "What are cognitive processes? an example-based approach," Synthese, vol. 194, no. 11, pp. 4251-4268, 2017.

[6] M.-C. Fellner, G. Volberg, M. Wimber, M. Goldhacker, M. W. Greenlee, and S. Hanslmayr, "Spatial mnemonic encoding: theta power decreases and medial temporal lobe bold increases co-occur during the usage of the method of loci," eneuro, vol. 3, no. 6, 2016.

[7] E. A. Maguire, E. R. Valentine, J. M. Wilding, and N. Kapur, "Routes to remembering: the brains behind superior memory," Nature neuroscience, vol. 6, no. 1, pp. 90-95, 2003.

[8] T. Dalgleish, L. Navrady, E. Bird, E. Hill, B. D. Dunn, and A.-M Golden, "Method-of-loci as a mnemonic device to facilitate access to self-affirming personal memories for individuals with depression," Clinical Psychological Science, vol. 1, no. 2, pp. 156-162, 2013.

[9] E. Fassbender and W. Heiden, "The virtual memory palace," Journal of Computational Information Systems, vol. 2, no. 1, pp. 457-464, 2006.

[10] J.-P. Huttner and R.-B. Susanne, "An immersive memory palace: supporting the method of loci with virtual reality," 2017.

[11] E. M. Wijma, M. A. Veerbeek, M. Prins, A. M. Pot, and B. M. Willemse, "A virtual reality intervention to improve the understanding and empathy for people with dementia in informal caregivers: results of a pilot study," Aging \& mental health, vol. 22, no. 9, pp. 1121-1129, 2018.

[12] R. Saracchini, C. C. Ortega, and L. Bordoni, "A mobile augmented reality assistive technology for the elderly," Comunicar. Media Education Research Journal, vol. 23, no. 2, 2015.

[13] O. Rosello, M. Exposito, and P. Maes, "Nevermind: using augmented reality for memorization," in Proceedings of the 29th Annual Symposium on User Interface Software and Technology, 2016, pp. 215-216.

[14] Ctrl-Group, "Exploring arkit for health," Sep 2017. [Online]. Available: https://www.ctrl-group.com/blog/2017/09/26/arkit

[15] A. R. UK. (2016) A walk through dementia. [Online]. Available: https://www.awalkthroughdementia.org/

[16] CamanioCare, "Bikearound," Sep 2019. [Online]. Available: https://www.camanio.com/us/products/bikearound/

[17] M. Larkin, "Bikearound: Making memories accessible and world travel feasible for all," The Journal on Active Aging, Aug 2018. 